\title{
Projeto Piloto - Implantação da Escala de Avaliação de Dor PAINAD (Pain Assessment In Advanced Dementia)
}

Siomara Tavares Fernandes Yamaguti , Tatiane Glória da Mota

\section{Introdução}

No processo demencial as pessoas podem deixar de interpretar sensações, como as dolorosas, muitas vezes por não serem capazes de recordar a sua dor ou por não serem capazes de comunicar -se verbalmente, o que torna mais difícil sua detecção e mensuração, caracterizando sua avaliação como um problema a ser considerado nesses pacientes.

Os estudos apontam para as dificuldades entre os profissionais de saúde de reconhecimento da dor e da sua avaliação em idosos com comprometimento cognitivo. Os instrumentos de medidas específicos, com base na observação de comportamentos que permitem identificar e avaliar a dor em pacientes não comunicativos tem sido uma solução para o melhor manejo da dor nessa população. A escala PAINAD (Pain Assessment in Advanced Dementia) foi adaptada culturalmente e traduzida para o português do Brasil em 2012. É baseada na avaliação do estado fisiológico e comportamental: respiração, vocalização, expressão facial, linguagem corporal e consolabilidade, com pontuações que variam de 0 a 2 para cada uma das cinco áreas avaliadas. É uma ferramenta simples. Sua pontuação varia de 0 a 10 , onde 1 a 3 pontos refere-se a uma dor leve, 4 a 6 : dor moderada e 7 a 10: dor forte.

\section{Objetivo}

Implantar o uso da escala PAINAD no complexo HCor para pacientes com comprometimento cognitivo no segundo semestre de 2018.

\section{Metodologia}

A escala será aplicada em março de 2018 nas unidades: $9^{\circ}$ 123 e UTI adulto, por um período de 20 dias com retirada de dúvidas "em loco" com a equipe de enfermagem. Seguirá a metodologia de avaliação do $\mathrm{IHI}$ (Institute for Healthcare Improvement) - modelo de programa de melhoria na prática clinica, seguindo o PDSA, onde P-PLAN planejar/ D-DO fazer/ S-Study estudar/ A-ACT fazer com base no estudo.

\section{Etapas em execução:}

\section{Resultados}

P: Fase de planejamento: definição das unidades pilotos/ reunião com os supervisores dos setores/ elaboração do cronograma: dias 08, 09, 11 e 12 de março de 2018 treinamento da equipe de enfermagem. Início do piloto: dia 14/03/2018, término 31/03/2018.

D: Fase de Treinamento: Reunião com educação permanente/ elaboração da aula/ treinamento dos colaboradores das áreas piloto.

\section{Para ser executado:}

S: Fase de esclarecimento das dúvidas/ revisão dos achados com a supervisão/ análise de prontuário por amostragem. A: Elaboração de relatórios e apresentação para os gestores. Após aprovação, implantação da escala na Instituição com cronograma de treinamento ( $2^{\circ}$ semestre de 2018).
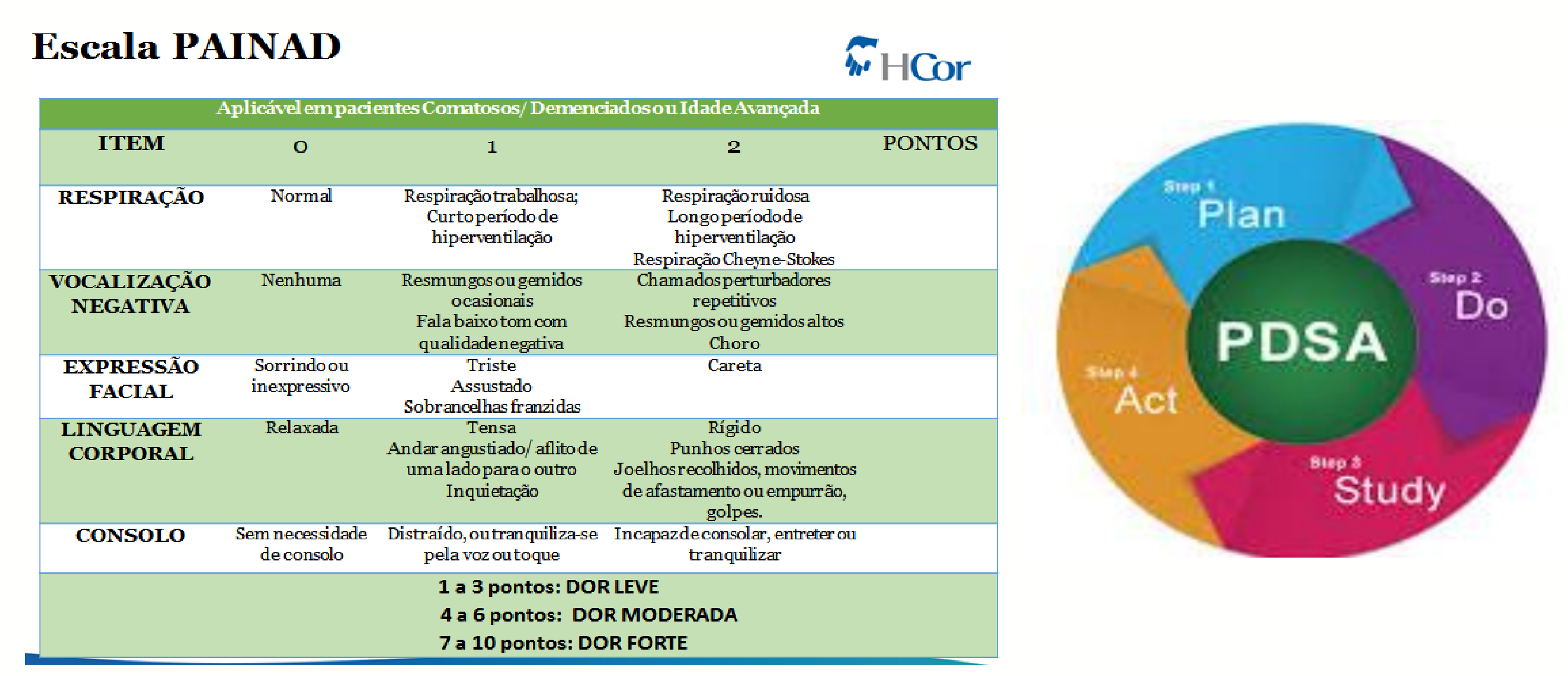

\section{Conclusão}

Esperamos com esse projeto piloto atingir o objetivo de implementar uma escala de avaliação de dor que atenda a população de idosos com comprometimento cognitivo e torne o gerenciamento da dor nesses pacientes mais eficaz.

\section{Referências Bibliográficas}

1. IHI Institute for Healthcare Improvement - modelo de programa de melhoria na prática clínica.

2. Lorenzet IC, Santos FC, Souza PMR, Gambarro RC, Coelho S, Cendoroglo MS. Avaliação da dor em idosos com demência: Tradução e adaptação transcultural PACSLAC para língua portuguesa. Rev. Bras. Med. 2011; 68 (4): 129-33

3. Valera GG, et al. Adaptação cultual para o Brasil da Escala Pain Assessment in Advanced Dementia - PAINAD.São Paulo: Revista

Escola de Enfermagem da USP 2014; 48 (3): 462-8. 